\title{
ERRATUM
}

Y. Li · D. Tan · H.P. Blaschek

\section{Molecular characterization and utilization of the CAK1 filamentous viruslike particle derived from Clostridium beijerinckif}

Published online: 12 February 2003

(C) Society for Industrial Microbiology 2003

\section{J Ind Microbiol Biotechnol (2002) 28:118-126}

The name of Douglas Tan was inadvertently omitted as an author of this paper.

The online version of the original article can be found at http:/ dx.doi.org/10.1038/sj/jim/7000225

Y. Li · D. Tan · H.P. Blaschek $(\bowtie)$

Biotechnology and Bioengineering Group,

Department of Food Science and Human Nutrition,

University of Illinois, 1207 West Gregory Drive,

Urbana, IL 61801, USA

E-mail: blaschek@uiuc.edu 